\title{
Efectos de la disminución de temperatura sobre el desarrollo de la pared de la antera y el grano de polen en Oryza sativa L.
}

\section{Effects of the temperature decrease on the development of the anther wall and pollen grain in Oryza sativa L.}

\author{
Verónica Fuentealba-Sandoval ${ }^{1 *}$, Víctor L. Finot ${ }^{1}$, Rosemarie Wilckens ${ }^{1}$ \& Patricio López- \\ SEPÚLVEDA ${ }^{2}$
}

1 Universidad de Concepción, Facultad de Agronomía, Casilla 537, Chillán, Chile.

2Universidad de Concepción, Facultad de Ciencias Naturales y Oceanográficas, Casilla 160-C, Concepción, Chile.

*verofuentealba@udec.cl

\begin{abstract}
RESUMEN
Se estudió el efecto de la disminución de temperatura de $30 / 20{ }^{\circ} \mathrm{C}$ (temperatura óptima) a $16{ }^{\circ} \mathrm{C}$ (temperatura baja) durante la etapa reproductiva en el desarrollo de la antera y el polen en los cultivares de arroz 'Diamante-INIA', 'Brillante-INIA' y 'Zafiro-INIA'. Los objetivos fueron describir los daños causados por estrés térmico a nivel ultraestructural y determinar la tolerancia relativa de los cultivares a la baja temperatura. Se cultivaron plantas en macetas a $30 / 20{ }^{\circ} \mathrm{C}$ (día/noche) y al iniciarse la formación de la panícula parte de éstas se trasladaron a $16{ }^{\circ} \mathrm{C}$ hasta antesis. Se recolectaron espiguillas en etapa de tétrada, micrósporas libres y polen maduro, y se realizaron cortes para microscopía óptica y electrónica de transmisión. A $30 / 20{ }^{\circ} \mathrm{C}$ se observó un desarrollo normal de los cuatro estratos de la pared de la antera (epidermis, endotecio, capa media y tapete) y de los granos de polen, mientras que a $16^{\circ} \mathrm{C}$ se observó hipertrofia del tapete, lóculos atrofiados, granos malformados, retraso de la antesis y disminución de la viabilidad. 'Diamante-INIA' se presentó como el cultivar menos tolerante a $16{ }^{\circ} \mathrm{C}$ y 'Zafiro-INIA' como el más tolerante.
\end{abstract}

Palabras clave: Desarrollo de la antera, desarrollo del polen, tolerancia a baja temperatura, tapete, microscopía electrónica de transmisión, viabilidad de polen.

\begin{abstract}
The effect of decreasing temperature from $30 / 20^{\circ} \mathrm{C}$ to $16^{\circ} \mathrm{C}$ during the reproductive stage on the development of the anther and pollen in rice 'Diamante-INIA', 'Brillante-INIA' and 'Zafiro-INIA', was studied. The objectives were to determine the relative tolerance of cultivars to low temperature and to describe cellular and ultrastructural damages caused by temperature stress. Plants were grown at $30 / 20{ }^{\circ} \mathrm{C}$, day/night (optimum temperature), and at panicle initiation some of these were moved to $16^{\circ} \mathrm{C}$ until anthesis. Spikelets were obtained at tetrad, free microspores and mature pollen stages, and sections were prepared for light and transmission electron microscopy. Normal development of the four layers of the anther wall (epidermis, endothecium, middle layer and tapetum) and of pollen grains were observed at $30 / 20{ }^{\circ} \mathrm{C}$, while at $16^{\circ} \mathrm{C}$ tapetal hypertrophy, atrophied locules, malformed grains, delayed anthesis and reduced pollen viability occurred. 'Diamante-INIA' was the less tolerant cultivar at $16^{\circ} \mathrm{C}$ and 'Zafiro-INIA' the most tolerant to temperature stress.
\end{abstract}

KEYwords: Anther wall development, pollen development, low temperature tolerance, tapetum, transmission electron microscopy, pollen viability.

\section{INTRODUCCIÓN}

El arroz (Oryza sativa L., Poaceae) es uno de los principales cultivos alimenticios del mundo, situándose en el segundo lugar de importancia entre los cereales a nivel mundial, después del trigo (IRRI 2002). Se cultiva en regiones tropicales así como en zonas de clima templado. En zonas templadas, las bajas temperaturas nocturnas $\left(<20^{\circ} \mathrm{C}\right)$ pueden afectar la germinación de la semilla así como el desarrollo de los órganos reproductivos (Castillo \& Alvarado 2002, Díaz et al. 2006), siendo la fase reproductiva la más sensible y donde se produce el mayor daño, lo que provoca reducción del rendimiento (Imin et al. 2006, Gothandam et al. 2007). Esta limitación de los rendimientos de arroz 
en las áreas templadas afecta especialmente a Corea, Japón, Australia, EE.UU y Chile (Alvarado \& Grau 1991, Shimono et al. 2002, Ortega 2007). En Chile, la reducción de rendimiento por bajas temperaturas fluctúa entre un $5 \mathrm{y}$ $10 \%$ en promedio. Sin embargo, períodos impredecibles de bajas temperaturas, que se producen cada 3 ó 4 años, pueden provocar pérdidas de 20 a $40 \%$ y en casos extremos hasta un $60 \%$ (Ortega 2007).

En Chile se cultiva Oryza sativa L. subsp. japonica S. Kato, que se desarrolla en climas templados y presenta mayor tolerancia a las bajas temperaturas que $O$. sativa subsp. indica S. Kato (Acevedo et al. 2008; Cruz et al. 2006, Jagadish et al. 2007, Kellog 2009). A la subsp. japonica pertenecen los cultivares 'Diamante-INIA', 'Brillante-INIA' y 'Zafiro-INIA', obtenidos en el programa de mejoramiento genético de arroz (PMGA) de INIA-Quilamapu, cuyo objetivo principal fue mejorar la tolerancia al frío, entre otros parámetros, la cual se manifiesta en un menor porcentaje de esterilidad floral (Cordero 2012). Evaluaciones de campo indican que estos cultivares presentan distintos niveles de tolerancia al frío, expresada como porcentaje de granos vanos en la panícula o "vanazón", determinando que 'ZafiroINIA' presenta menor esterilidad floral que 'BrillanteINIA' y éste menor que 'Diamante-INIA' (Alvarado et al. 1997, Ortega 2007). El desarrollo reproductivo es sensible al estrés abiótico, no sólo en arroz, sino también en otras especies de cereales, como trigo y maíz (Saini \&Westgate 2000, Cruz et al. 2008).

La etapa reproductiva comienza con la iniciación de la panícula; en arroz, la diferenciación del polen es la etapa más sensible a las bajas temperaturas (Acevedo et al. 2008). La etapa de inicio de panícula se reconoce a simple vista cuando se alinea el nudo de la hoja bandera con la hoja anterior, es decir están en el mismo nivel o posición 0 . La disminución de la temperatura, durante la etapa de inicio de panícula o mientras ocurre la diferenciación del polen puede producir malformaciones a nivel de la pared de la antera y causar esterilidad masculina (Alvarado \& Grau 1991). Entre las alteraciones que aparecen en el cultivo, producto de la exposición a bajas temperaturas, puede mencionarse deformación de las células de la pared de la antera, hipertrofia de células tapetales, retraso del estado de bota, degeneración de las espiguillas, menor producción de granos, crecimiento reducido y deformación de los granos de polen, exserción incompleta de la panícula, retraso de la antesis y esterilidad de los granos de polen (Díaz et al. 2006, Acevedo et al. 2008).

En Chile la esterilidad de polen en arroz se ha investigado en términos de medición de granos vanos por panícula, causada ya sea por bajas temperaturas y/o asociada a factores de manejo agronómico como fertilización nitrogenada, fechas de siembra y alturas de agua en los cuadros de cultivo (Ortega 2007). El estudio a nivel celular se considera una herramienta poderosa para validar los síntomas visibles a nivel macroscópico tales como rendimiento en grano, porcentaje de esterilidad de espiguilla (granos vanos) y exserción de la panícula, producto de las bajas temperaturas en la etapa reproductiva. A su vez, esta evaluación podría contemplarse como una herramienta adicional, al momento de seleccionar genotipos para mejorar la tolerancia al frío.

Dada la importancia del tapete en el desarrollo del polen, se considera de manera general que cualquier alteración en este tejido produce anormalidades en los granos de polen. Observaciones citológicas de anteras muestran que este estrato es el más sensible al estrés por bajas temperaturas, manifestándose una hipertrofia del tejido asociada a pérdida funcional del mismo y, con ello, a esterilidad del polen (Gothandam et al. 2007). Se sugiere que esta anomalía tiene relación con la forma o arreglo del retículo endoplásmico. Así, el arreglo en pilas de sacos aplanados es considerado un patrón normal, mientras que la forma circular se asocia a esterilidad de polen (Imin et al. 2006, Mamun et al. 2006, Gothandam et al. 2007).

En este trabajo se describe el desarrollo de la pared de la antera y de la pared del polen en tres cultivares de arroz producidos en Chile: 'Diamante-INIA', 'BrillanteINIA' y 'Zafiro-INIA'. El objetivo general fue evaluar la tolerancia al frío de estos tres cultivares expuestos a baja temperatura $\left(16{ }^{\circ} \mathrm{C}\right)$ durante la etapa reproductiva. Los objetivos específicos fueron: 1) describir y comparar el desarrollo de la pared de la antera, 2) describir y comparar el desarrollo de la pared del grano de polen a nivel anatómico y ultraestructural, utilizando microscopía óptica (MO) y electrónica de transmisión (MET) y 3) evaluar el porcentaje de germinación y viabilidad de granos de polen en el período de antesis en los cultivares 'Diamante-INIA', 'BrillanteINIA' y 'Zafiro-INIA'.

\section{MATERIALES Y MÉTODOS}

Material Vegetal y CONDiCiONeS DE CRECIMIENTO Plantas de los cultivares 'Diamante-INIA', 'BrillanteINIA' y 'Zafiro-INIA' fueron cultivadas en macetas de 2 L de capacidad con suelo arcilloso (serie Quella, Thermic Aquic Durixererts) (Stolpe 2006). Se utilizaron 18 macetas (6 macetas con 5 plantas cada una por cada cultivar), las cuales se llevaron a invernadero a $30 / 20{ }^{\circ} \mathrm{C}$ (día/noche), sin limitaciones de riego ni nutrientes. Una vez que las plantas cultivadas en invernadero a $30 / 20^{\circ} \mathrm{C}$ se encontraron en estado de inicio de panícula (IP), tres macetas de cada cultivar se sometieron a $16{ }^{\circ} \mathrm{C}$ constante en una cámara de crecimiento, permaneciendo allí hasta la antesis y las restantes se mantuvieron a $30 / 20^{\circ} \mathrm{C}$ (control).

OBTENCIÓN, FIJACIÓN E INCLUSIÓN DE ANTERAS

Durante la etapa reproductiva, tanto en las plantas cultivadas a $16{ }^{\circ} \mathrm{C}$ como a $30 / 20{ }^{\circ} \mathrm{C}$, se realizaron tres muestreos 
para obtener material que posteriormente se utilizó en los estudios de microscopía. Éstos se realizaron considerando los parámetros definidos por Counce et al. (2000): 1) R0, corresponde a inicio de panícula (IP). En éste la panícula no supera 1 - $2 \mathrm{~mm}$ de longitud y ocurre 50 - 70 días después de la germinación; 2) R2, diferenciación del polen (DP). Éste ocurre cuando se alinea el nudo de la hoja bandera y la hoja anterior. 3) R4, antesis. Ocurre alrededor de 30 días después de IP y en la panícula del tallo principal se observan una o más espiguillas en antesis.

Los muestreos de panícula se realizaron: 10 días después de $\mathrm{R} 0$ (antes DP); 20 días después de R0 (después de DP) y 30 días después de R0 (antesis). En ellos se recolectó una panícula de cada maceta correspondiente a cada cultivar, en los dos tratamientos de temperatura. Luego, se extrajo 5 espiguillas del tercio medio de cada panícula. Las anteras extraídas de las espiguillas fueron fijadas en solución Karnovsky (glutaraldehído al 2,5\%, paraformaldehído al $2 \%$ y buffer fosfato $0,1 \mathrm{M}(\mathrm{pH} 7,4)$ ) (Gothandam et al. 2007). Después de la fijación, las anteras fueron postfijadas en tetróxido de osmio al $1 \%$ (p:v) durante $2 \mathrm{~h}$ a $4{ }^{\circ} \mathrm{C}$. Posteriormente, fueron deshidratadas usando una serie de acetona (30 a $100 \%$ (v:v)) por $30 \mathrm{~min}$ cada una e incluidas en Araldita $\left(60^{\circ} \mathrm{C}\right.$ por $12 \mathrm{~h}$ ) (Bozzola \& Russell 1999).

OBTENCIÓN DE CORTES PARA MICROSCOPÍA

Cortes semifinos (900 a $1000 \mathrm{~nm}$ de espesor) fueron realizados empleando un ultramicrótomo Sorvall MT 2-B. Las secciones obtenidas se depositaron sobre portaobjetos y se tiñeron con azul de toluidina. Cortes ultrafinos ( 40 a $50 \mathrm{~nm}$ de espesor) fueron realizados empleando un ultramicrótomo Sorvall MT 5000. Estos fueron recogidos en grillas de cobre y teñidos con acetato de uranilo al 2,5\% (p:v) por $20 \mathrm{~min}$. Luego, las grillas fueron lavadas con agua destilada y se tiñeron con citrato de plomo por $7 \mathrm{~min}$. Los cortes semifinos de anteras se observaron y fotografiaron con un fotomicroscopio Zeiss, Axiostar plus. Los cortes ultrafinos se observaron con un microscopio electrónico de transmisión JEOL/JEM 1200 EX II. Las mediciones en las imágenes obtenidas con el MET se llevaron a cabo con el programa de morfometría geométrica TPSDig, versión 2.0.

TEST DE VIABILIDAD Y GERMINACIÓN DE GRANOS DE POLEN En etapa de antesis, se realizó tinción de las anteras con tetrazolio en solución acuosa $1 \%(\mathrm{p} / \mathrm{v})$ cloruro de 2,3,5 trifeniltetrazolio en $50 \%$ de sacarosa a $28{ }^{\circ} \mathrm{C}$, en oscuridad durante $1 \mathrm{~h}$ (Gothandam et al. 2007). Las anteras se observaron utilizando un microscopio óptico y se consideró polen viable aquel que se tiñó de color rojo y no viable el que no logró teñirse (Gothandam et al. 2007, Peterson et al. 2010). La determinación del porcentaje de viabilidad se realizó con el objetivo de 40x y se consideró un tamaño de muestra de 200 - 250 granos de polen. Se evaluaron cuatro anteras provenientes de dos espiguillas de cada maceta de cada cultivar y se calculó el promedio, el cual correspondió al porcentaje de viabilidad de cada cultivar.

La germinación in vitro se realizó empleando el método de Khatun \& Flowers (1995), en un medio de germinación artificial conteniendo $20 \mathrm{~g}$ de sacarosa y $0,02 \mathrm{~g}$ de ácido bórico en $100 \mathrm{~mL}$ de agua destilada. En un portaobjetos cóncavo se agregó una alícuota del medio y en él se depositaron granos de polen procedentes de las anteras restantes de las espiguillas utilizadas en el test de viabilidad. Éstos se llevaron a una cámara de crecimiento a $20{ }^{\circ} \mathrm{C}$ por $24 \mathrm{~h}$, para posteriormente con un microscopio óptico con el objetivo de $5 \mathrm{x}$, observar 5 campos visuales y calcular el porcentaje de granos germinados. Así, se obtuvo un valor promedio, el cual representó el porcentaje de germinación. Se consideró germinados aquellos en que el tubo polínico presentó una longitud igual o mayor al diámetro del grano de polen.

\section{RESULTADOS}

En las observaciones de los cortes provenientes de plantas cultivadas, tanto a temperatura de $16{ }^{\circ} \mathrm{C}$ como a $30 / 20{ }^{\circ} \mathrm{C}$, se determinó que en el primer muestreo (diez días después de estado R0) el polen se encontraba en la etapa de tétrada (Figs. 1A-C y 2A-C); en el segundo muestreo (veinte días después de estado R0) en la etapa de micrósporas libres (Figs. 1D-F y 2D-F); y en el tercer muestreo (estado de R4) en la etapa de polen maduro (Figs. 1G-I y 2G-I).

\section{Desarrollo de la PAREd de la ANTERA}

\section{ETAPA DE MICRÓSPORAS LIBRES}

Las anteras de los tres cultivares sometidos a $16{ }^{\circ} \mathrm{C}$ presentaron una estrangulación que tiende a dividir en dos cada uno de los cuatro lóculos (Fig. 1A-C, punta de flecha), cambiando la forma normal circular de la sección transversal del lóculo desarrollada a $30 / 20^{\circ} \mathrm{C}$ (Fig. 2A-C). En la pared de la antera sólo se distinguieron tres de los cuatro estratos celulares presentes a $30 / 20{ }^{\circ} \mathrm{C}$ (epidermis, endotecio, capa media y tapete) debido a la ausencia de la capa media, y a su vez los mismos presentaron un aspecto contraído. En ambos casos se observó la presencia de micrósporas en el interior de los lóculos.

A $30 / 20{ }^{\circ} \mathrm{C}$, en la antera se encuentran presentes los cuatro estratos de la pared (Figs. 2D-F y 3A-C) y en el interior del lóculo se observan micrósporas esféricas con apariencia normal, mientras que a $16{ }^{\circ} \mathrm{C}$ en 'DiamanteINIA' y 'Brillante-INIA' se observaron tres estratos, los cuales se observan contraídos. Esta alteración se presenta en la mayor parte de los lóculos, en los que se observó micrósporas atrofiadas o con forma de medialuna (Figs. 1D, E, asterisco y 4J-K). 'Diamante-INIA' fue el cultivar que presentó mayor alteración, con tres de los cuatro 
lóculos de la antera con desarrollo anormal asociado a un menor tamaño, los cuales presentaron casi la totalidad de sus granos atrofiados (Fig. 1D). En los tres cultivares, en algunos sectores del estrato tapetal se observó hipertrofia del tejido hacia el interior del lóculo (Fig. 1D-F, flechas) asociada a la ausencia de granos o deformación de éstos. En 'Brillante-INIA' se observó un lóculo totalmente atrofiado, tanto a nivel de los estratos que conforman la pared como en su contenido (Fig. 1E), el cual se presentó contraído y sin granos de polen, ya que su interior estaba ocupado en su totalidad por el tapete. A diferencia de 'Diamante-INIA' y 'Brillante-INIA', 'Zafiro-INIA' presentó un desarrollo normal de los cuatro lóculos de la antera, tanto en forma como en los estratos que conforman la pared. Los granos de polen contenidos en su mayoría presentaron aspecto normal, aunque se observó algunos sectores con granos deformes o de menor tamaño en las zonas en que el estrato tapetal se observa hipertrofiado (Fig. 1F, flechas).

Los estratos de la pared de la antera a $30 / 20^{\circ} \mathrm{C}$ presentaron las siguientes características: epidermis uniestratificada y con células redondeadas; endotecio uniestratificado con células rectangulares y aplanadas en corte transversal; la capa media como un estrato delgado formado por células efímeras que colapsan tempranamente; tapete, que corresponde al estrato más interno en contacto directo con el tejido esporógeno, constituido por una capa de células de espesor irregular, ya que en los sectores en contacto directo con los granos está muy reducido y en las zonas entre granos presenta mayor desarrollo (Fig. 3A, B, C).

Producto de la exposición de las plantas a $16{ }^{\circ} \mathrm{C}$ se

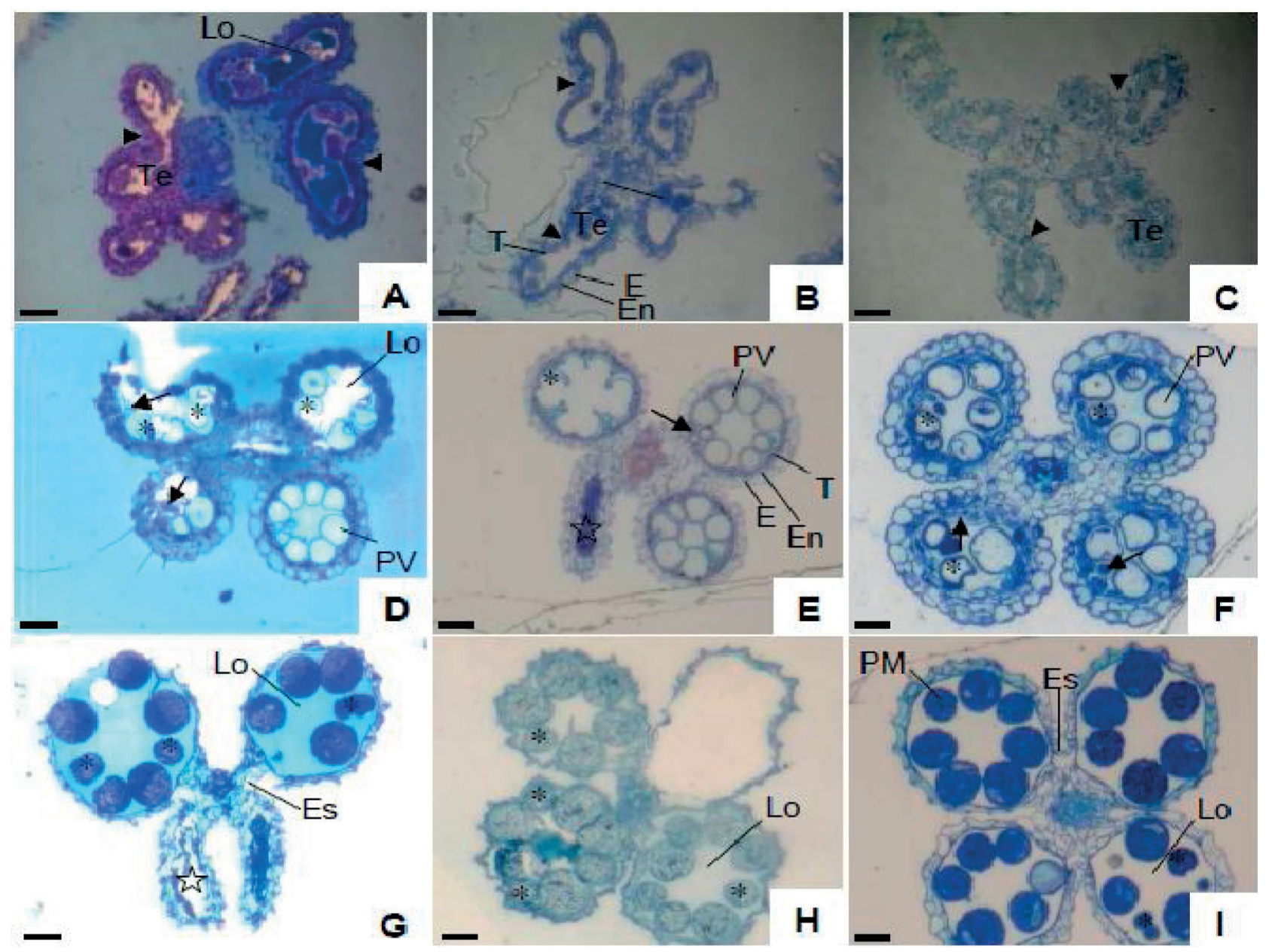

Figura 1. Fotomicrografías (MO) del desarrollo de antera de arroz a $16{ }^{\circ} \mathrm{C} . \mathrm{A}, \mathrm{D}, \mathrm{G}$. 'Diamante-INIA'. B, E, H. 'Brillante-INIA'. C, F, I. 'Zafiro-INIA'. A - C, etapa de tétrada; D - F, micrósporas libres; G - I, polen maduro. E, epidermis; En, endotecio; CM, capa media; T, tapete; Te, tétrada; Lo, lóculo; PV, polen vacuolado; PM, polen maduro; Es, estomio. Flecha indica hipertrofia del tapete; punta de flecha

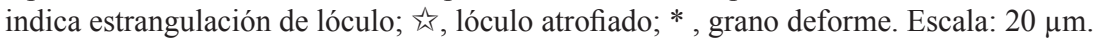

FIGURE 1. Photomicrographs (MO) of anther development in rice cultivated at $16^{\circ} \mathrm{C}$. A, D, G. 'Diamante-INIA'. B, E, H. 'Brillante-INIA'. C, F, I. 'Zafiro-INIA'. A - C, Tetrad stage; D - F, free microspores; G - I, mature pollen. E, epidermis; En, endothecium; CM, middle layer; T, tapetum; Te, tetrad; Lo, locule; PV, vacuolated pollen; PM, mature pollen; Es, stomium. Arrow indicates swelling of tapetum; arrowhead indicate strangulation of locule; $\hat{\kappa}$, stunted locule; *, deformed grain. Scale: $20 \mu \mathrm{m}$. 
observaron variaciones tanto en el espesor de los estratos de la pared de la antera como de la pared del futuro grano de polen. El espesor de los estratos de la pared de la antera en la etapa de micrósporas libres en los cultivares 'Diamante-INIA' y 'Brillante-INIA' disminuyó, siendo esta disminución más acentuada en 'Diamante-INIA', mientras que en 'Zafiro-INIA' aumentó el espesor de todos los estratos, principalmente del tapete (Tabla I). El tapete fue el estrato más afectado por la exposición de plantas de arroz a $16{ }^{\circ} \mathrm{C}$, manifestando cambios marcados en el espesor, con zonas entre los granos con tendencia a invadir el lóculo. En las zonas en que el tapete presentó desarrollo anormal se observó un retículo endoplásmico (RE) con morfología atípica. El arreglo en pilas de cisternas o sacos aplanados se consideraba el patrón normal en tanto en 'Diamante-INIA' presentó forma circular (Fig. 5A), 'Brillante-INIA' forma serpenteado-ondulada (Fig. 5B) y 'Zafiro-INIA' forma ondulada con tendencia a formar pilas de sacos aplanados (Fig. 5C). En las zonas cercanas al RE se observó la presencia de otros organelos como plastidios, mitocondrias y glóbulos de lípidos (Fig. 5D, E, F).

\section{ETAPA DE POLEN MADURO}

A $30 / 20{ }^{\circ} \mathrm{C}$ los estratos se reducen a tres, siendo éstos la epidermis, endotecio y tapete, ya que la capa media se encuentra totalmente consumida. El tapete se presenta consumido; sólo quedan restos celulares y la membrana tapetal con los orbículas recubriendo el interior del lóculo (Fig. 3G-I). Los lóculos mantienen la forma circular normal en corte transversal y en su interior contienen granos de

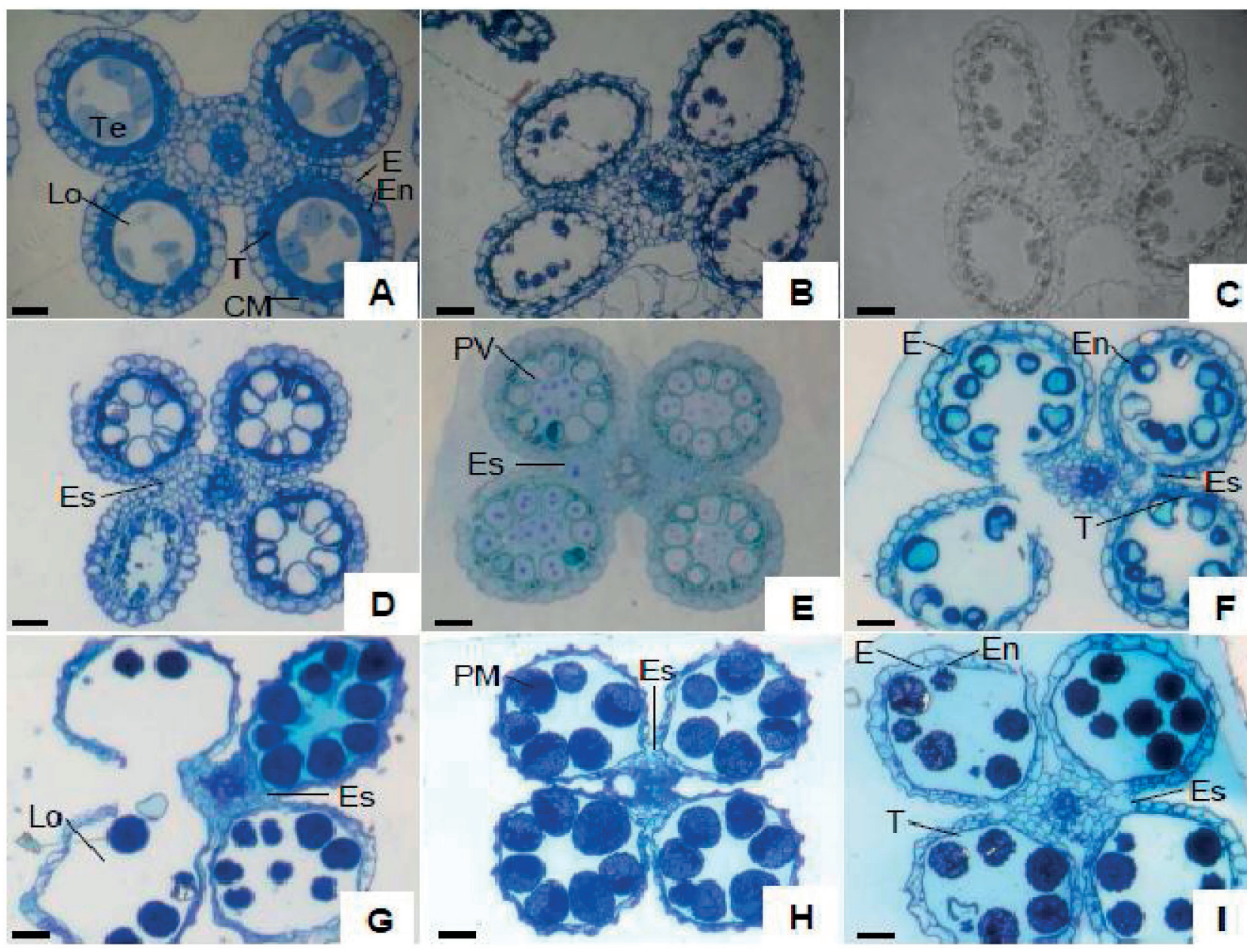

Figura 2. Fotomicrografías (MO) del desarrollo de antera de arroz a 30/20 ㄷ. A, D, G. 'Diamante-INIA'. B, E, H. 'Brillante-INIA'. C, F, I. 'Zafiro-INIA'. A - C, etapa de tétrada; D - F, micrósporas libres; G - I, polen maduro. E, epidermis; En, endotecio; CM, capa media; T, tapete; Te, tétrada; Lo, lóculo; PV, polen vacuolado; PM, polen maduro; Es, estomio. Escala: $20 \mu \mathrm{m}$.

Figure 2. Photomicrographs (MO) of anther development in rice cultivated at $30 / 20^{\circ} \mathrm{C}$. A, D, G. 'Diamante-INIA'. B, E, H. 'BrillanteINIA'. C, F, I. 'Zafiro-INIA'. A - C, Tetrad stage; D - F, free microspores; G - I, mature pollen. E, epidermis; En, endothecium; CM, middle layer; T, tapetum; Te, tetrad; Lo, locule; PV, vacuolated pollen; PM, mature pollen; Es, stomium. Scale: $20 \mu \mathrm{m}$. 

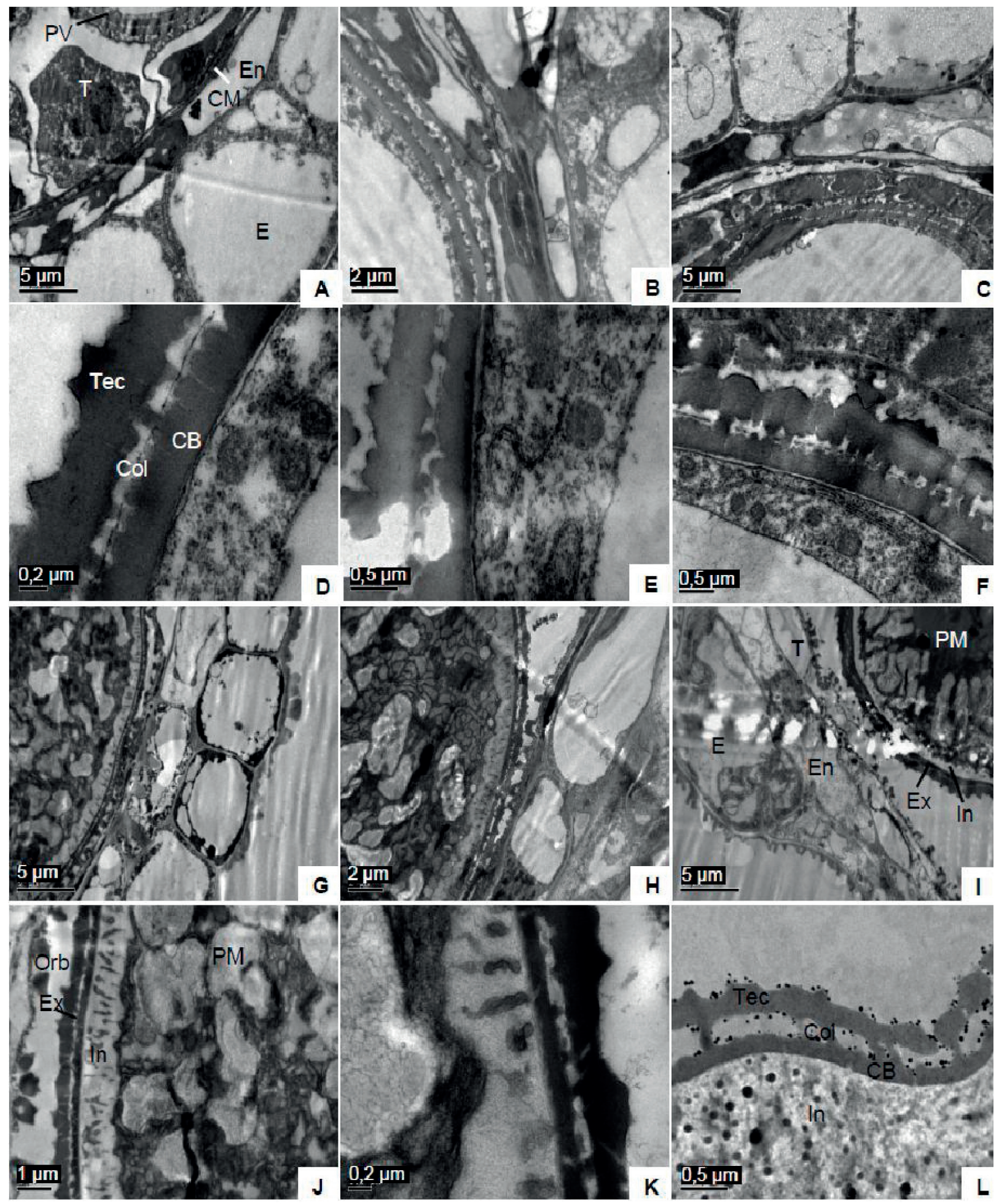

FiguRA 3. Fotomicrografías (MET) de la pared de la antera y exina de tres cultivares de arroz a 30/20 ${ }^{\circ} \mathrm{C}$. A, D, G, J. 'Diamante-INIA'. B, E, H, K. 'Brillante-INIA'. C, F, I, L. 'Zafiro-INIA'. A - F, micrósporas libres; G - L, polen maduro. E, epidermis; En, endotecio; CM, capa media; T, tapete; Orb, orbículas; PV, polen vacuolado; PM, polen maduro; Ex, exina; Tec, tectum; Col, columela; CB, capa basal; In, intina.

FiguRE 3. Photomicrographs (MET) of anther wall and exine of three rice cultivars cultivated at $30 / 20{ }^{\circ} \mathrm{C}$. A, D, G, J. 'Diamante-INIA'. B, E, H, K. 'Brillante-INIA'. C, F, I, L. 'Zafiro-INIA'. A - F, free microspores; G - L, mature pollen. E, epidermis; En, endothecium; CM, middle layer; T, tapetum; Orb, orbicules; PV, vacuolated pollen; PM, mature pollen; Ex, exine; Tec, tectum; Col, columella; CB, foot layer; In, intine. 
polen maduros 2-celulares (Fig. 2G-I), que se caracterizan por formación completa de la pared (Fig. 3J-L). La epidermis está formada por células redondeadas a aplanadas, y están recubiertas por una cutícula estriada. Debajo de este estrato se observó el endotecio, con células regulares de forma rectangular (Fig. 3G-I). En la cara interna del tapete se observa una membrana tapetal con orbículas o cuerpos de Ubisch (Fig. 3J), de forma esférica a subesférica, con espículas superficiales y un corazón central transparente a los electrones.

A $16{ }^{\circ} \mathrm{C}$ siguieron presentes los mismos tres estratos de la etapa anterior. Sin embargo, en 'Diamante-INIA' dos de los cuatro lóculos de la antera están totalmente atrofiados, mostrándose contraídos y con ausencia total de granos (Fig. $1 \mathrm{G}$, estrella), mientras que en los lóculos con desarrollo normal se observó algunos granos de polen deformes, de menor tamaño (Fig. 1G, asterisco). Así, al igual que en la etapa de micrósporas libres, este cultivar continúa siendo el más afectado por la exposición a $16{ }^{\circ} \mathrm{C}$ durante la etapa reproductiva. En 'Brillante-INIA' también se observó daño a nivel del lóculo, aunque en menor medida que en 'Diamante-INIA', presentándose como una deformación

TABLA I. Espesor $(\mu \mathrm{m})$ de los estratos de la pared de la antera en etapa de micrósporas libres en tres cultivares de arroz a $30 / 20{ }^{\circ} \mathrm{C}$ y $16{ }^{\circ} \mathrm{C}$ durante la etapa reproductiva.

TABle I. Thickness $(\mu \mathrm{m})$ of the anther wall layers in free microspores stage in three rice cultivars at $30 / 20{ }^{\circ} \mathrm{C}$ and $16{ }^{\circ} \mathrm{C}$ during the reproductive stage.

\begin{tabular}{lccc}
\hline ETAPA DE MICRósPora Libre & 'Diamante- INIA' & 'Brillante- INIA' & 'Zafiro- INIA' \\
\cline { 2 - 4 } $30 / 20^{\circ} \mathrm{C}$ & $9,0-12,0$ & & \\
Epidermis & $2,0-4,0$ & $7,5-9,5$ & $9,5-10,5$ \\
Endotecio & $1,0-2,0$ & $2,0-3,0$ & $3,5-4,0$ \\
Capa media & $2,0-4,5$ & $1,0-2,0$ & $1,0-2,0$ \\
Tapete (contacto con grano) & $6,0-10,0$ & $2,0-4,0$ & $2,5-3,0$ \\
Tapete (entre granos) & & $6,0-8,5$ & $4,0-5,0$ \\
$16^{\circ} \mathrm{C}$ & $4,0-5,5$ & & \\
Epidermis & $1,5-2,5$ & $4,5-7,0$ & $10,0-12,0$ \\
Endotecio & $1,0-1,5$ & $2,0-3,0$ & $4,5-5,5$ \\
Capa media & $1,3-1,6$ & $1,2-1,6$ & $1,0-2,5$ \\
Tapete (contacto con grano) & $5,0-6,0$ & $1,5-1,8$ & $4,0-4,5$ \\
Tapete (entre granos) & & $4,0-8,0$ & $6,5-8,0$ \\
\hline
\end{tabular}

TABLA II. Espesor $(\mu \mathrm{m})$ de los estratos de la pared de la antera en etapa de polen maduro en tres cultivares de arroz a $30 / 20{ }^{\circ} \mathrm{C}$ y $16{ }^{\circ} \mathrm{C}$ durante la etapa reproductiva.

TABLE II. Thickness $(\mu \mathrm{m})$ of anther wall layers in mature pollen stage in three rice cultivars to $30 / 20{ }^{\circ} \mathrm{C}$ and $16{ }^{\circ} \mathrm{C}$ during the reproductive stage.

\begin{tabular}{lccc}
\hline ETAPA DE POLEN MAdURO & 'Diamante- INIA' & 'BRILLANTE- INIA' & 'ZAFiro- INIA' \\
\cline { 2 - 4 }$\underline{30 / 20^{\circ} \mathrm{C}}$ & & & \\
Epidermis & $6,5-7,0$ & $5,0-8,0$ & $3,5-4,0$ \\
Endotecio & $4,0-4,5$ & $3,5-4,0$ & $3,0-3,5$ \\
Tapete (contacto con grano) & $2,0-3,0$ & $1,5-2,0$ & $1,0-1,5$ \\
Tapete (entre granos) & Ausente & Ausente & Ausente \\
$\underline{16{ }^{\circ} \mathrm{C}}$ & & & \\
Epidermis & $4,5-6,0$ & $3,0-5,0$ & $2,0-3,5$ \\
Endotecio & $4,0-4,5$ & $1,0-1,5$ & $1,0-1,5$ \\
Tapete (contacto con grano) & $1,0-1,3$ & $0,5-1,0$ & $0,5-0,6$ \\
Tapete (entre granos) & $2,0-4,0$ & Ausente & Ausente \\
\hline
\end{tabular}



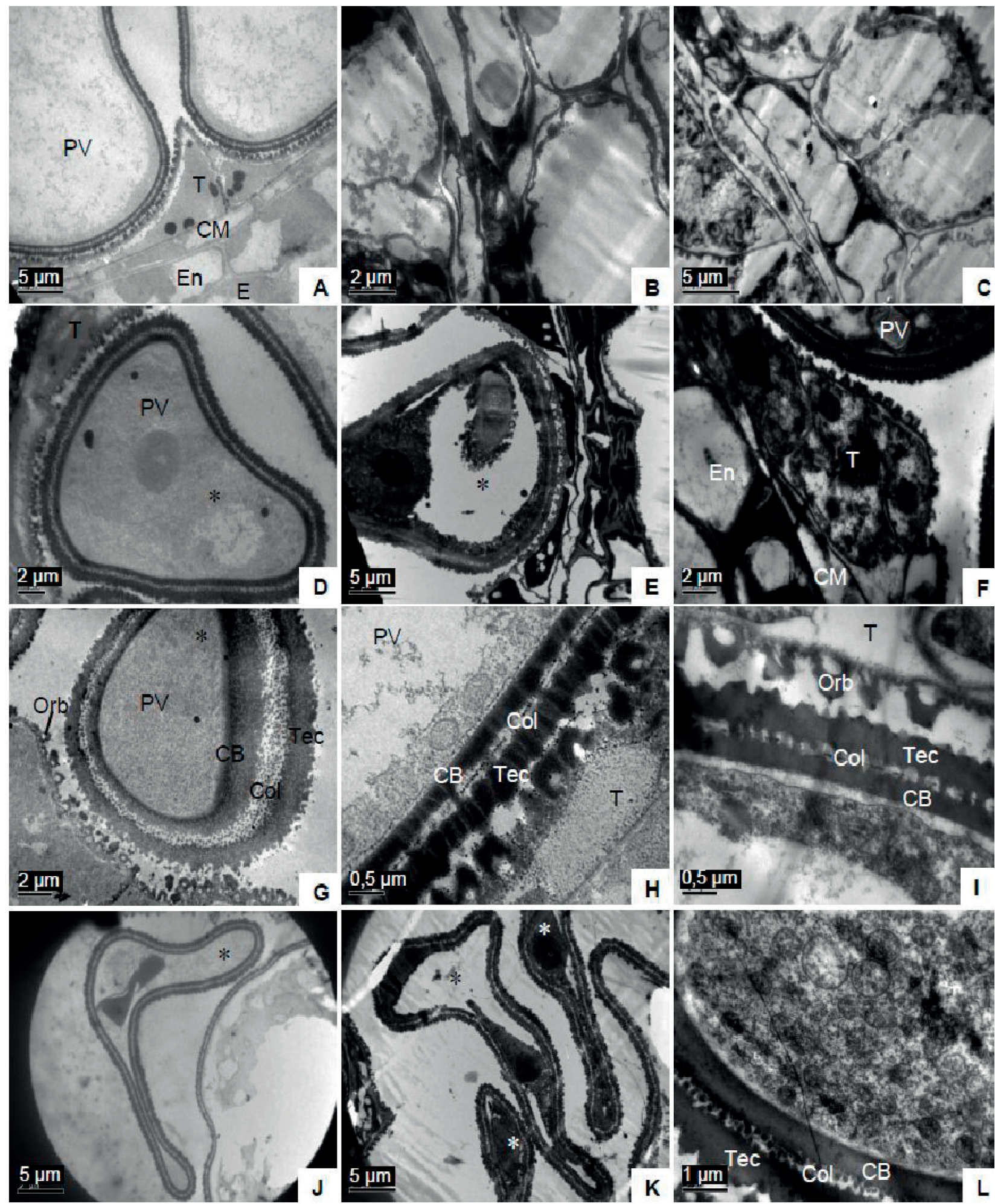

Figura 4. Fotomicrografías (MET) de la pared de la antera y exina en etapa de micrósporas libres, de tres cultivares de arroz a $16^{\circ} \mathrm{C}$. A, D, G, J. 'Diamante-INIA'. B, E, H, K. 'Brillante-INIA'. C, F, I, L. 'Zafiro-INIA'. E, epidermis; En, endotecio; CM, capa media; T, tapete; Orb, orbículas; PV, micrósporas; Tec, Tectum; Col, columela; $\mathrm{CB}$, capa basal; * , grano deforme.

Figure 4. Photomicrographs (MET) of anther wall and exine in free microspores stage, of three rice cultivars to $16{ }^{\circ} \mathrm{C}$. A, D, G, J. 'Diamante-INIA'. B, E, H, K. 'Brillante-INIA'. C, F, I, L. 'Zafiro-INIA'. E, epidermis; En, endothecium; CM, middle layer; T, tapetum; Orb, orbicules; PV, microspores; Tec, Tectum; Col, columella; CB, foot layer; * , deformed grain. 

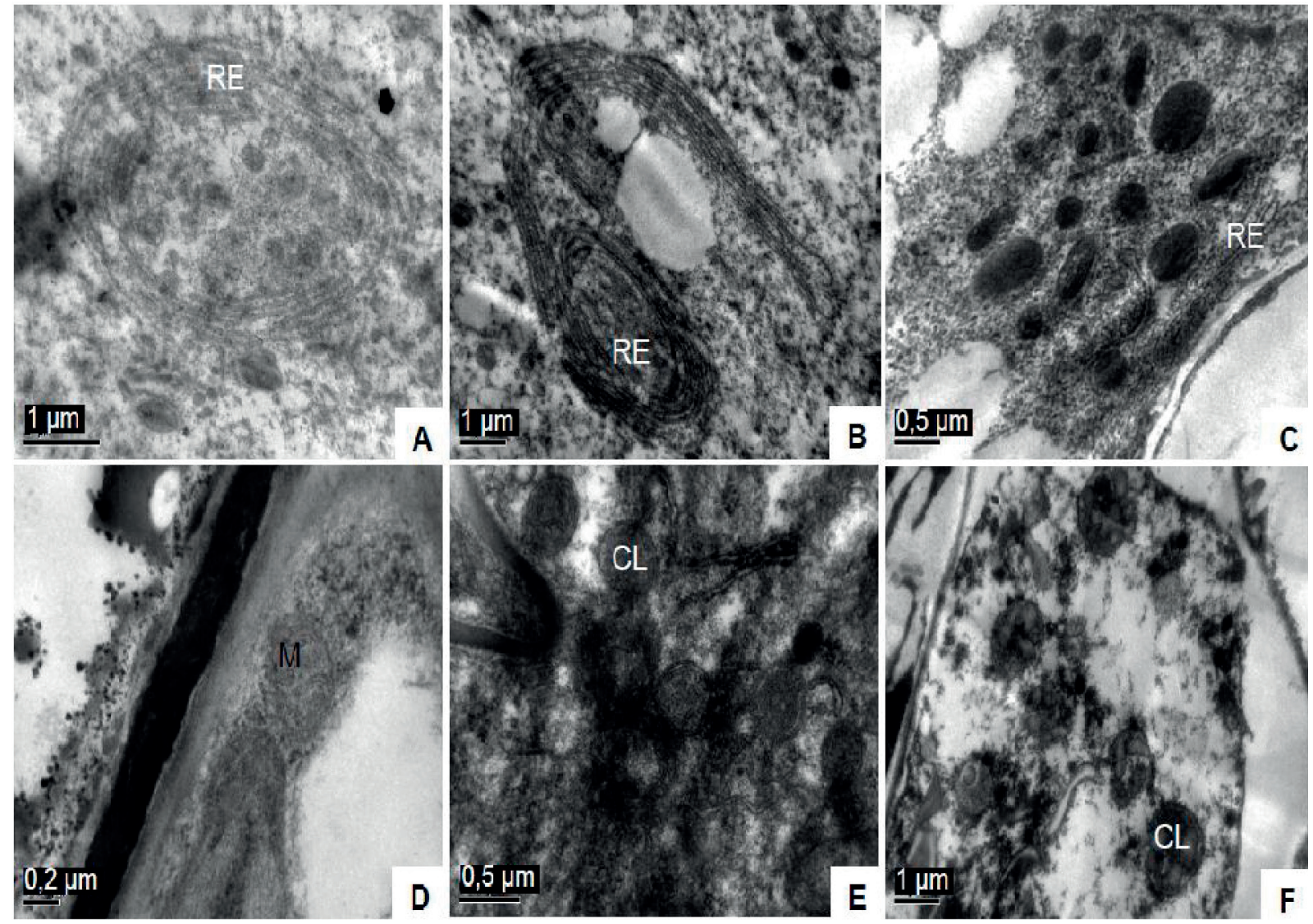

Figura 5. Fotomicrografías (MET) de tapete en etapa de micrósporas libres de tres cultivares de arroz a $16^{\circ} \mathrm{C}$. A, D. 'Diamante-INIA'. B, E. 'Brillante-INIA'. C, F. 'Zafiro-INIA'. RE, retículo endoplásmico; CL, cuerpos de lípidos; M, mitocondria.

Figure 5. Photomicrographs (MET) of tapetum in free microspores stage of three rice cultivars to $16{ }^{\circ} \mathrm{C}$ during the reproductive stage. A, D. 'Diamante-INIA'. B, E. 'Brillante-INIA'. C, F. 'Zafiro-INIA'. RE, endoplasmic reticulum; CL, lipidbodies; M, mitochondria.

que modifica la forma circular típica, adoptando con ello un aspecto irregular. Este daño se acompaña de una ausencia total de granos (Fig. 1H) o presencia de un contenido mínimo de los mismos. Por otro lado, en 'Zafiro-INIA' se observó desarrollo casi normal del lóculo y granos de polen. En éste, dos lóculos presentaron menor tamaño y algunos granos de polen con tamaño reducido (Fig. 1I).

Los estratos que conforman la pared de la antera a 16 ${ }^{\circ} \mathrm{C}$ presentaron un menor espesor respecto a $30 / 20{ }^{\circ} \mathrm{C}$ (Tabla II). La epidermis en los tres cultivares disminuyó entre $30-40 \%$ y no se observó como un estrato formado por células redondeadas, ya que producto de la disminución de temperatura adquirieron una forma más bien aplanada y contraída en corte transversal. A su vez, 'Diamante-INIA' posee estriaciones de la cutícula más desarrolladas que 'Brillante-INIA' y 'Zafiro-INIA' (Fig. 6A-C). El endotecio disminuyó entre $60-70 \%$ en los cultivares 'Brillante-INIA' y 'Zafiro-INIA' (Tabla II), mientras que en 'Diamante-INIA' se mantuvo el espesor. $\mathrm{Al}$ exponer las plantas de arroz a 16 ${ }^{\circ} \mathrm{C}$ el espesor de éste disminuyó entre 50-60\%. Por otro lado, en este estrato se destacó la presencia de orbículas, los cuales fueron más abundantes en 'Diamante-INIA' (Fig. 6A).

DesarRollo de LA PARED DEL GRANo DE POLEN

ETAPA DE MICRÓSPORAS LIBRES

En esta etapa, tanto a $16^{\circ} \mathrm{C}$ como a $30 / 20^{\circ} \mathrm{C}$, la micróspora presentó un citoplasma ocupado casi en su totalidad por una gran vacuola (Figs. 1D-F y 2D-F) y exina desarrollada (Figs. 3A-F y 4A-L) diferenciada en tectum, columela (infratectum) y capa basal (Figs. 3D-F y 4G-I). En ambas condiciones de temperatura el tectum es continuo e irregular. La capa basal o foot-layer se observó continua, granular y con un espesor similar al tectum (Figs. 4G-I y 6D-F).

Dado que en la exina se reconoció la presencia de tectum, columela y capa basal, con ausencia de endexina, se determinó que la exina presente en los tres cultivares de arroz estudiados es completamente ectexinosa.

$\mathrm{Al}$ exponer las plantas a $16{ }^{\circ} \mathrm{C}$ ocurrió deformación del grano del polen, ya sea en su totalidad o parcialmente, afectando la porción correspondiente a la pared, 
especialmente en los cultivares 'Diamante-INIA' y 'Brillante-INIA' (Fig. 1D-E, asterisco), mientras que el daño en 'Zafiro-INIA' se relacionó con granos de menor tamaño (Fig. 1F, asterisco). La variación en la forma de los granos se manifestó como un cambio desde la forma esférica, observada a $30 / 20{ }^{\circ} \mathrm{C}$ (Fig. 2D-F), a granos deformes, con hendiduras en sus costados, adquiriendo así forma de medialuna, triangular o simplemente aspecto contraído (Figs. 1D-F y 4J, K). A su vez, el espesor de la pared del grano de polen aumentó en los tres cultivares, siendo esto más notorio en el cultivar 'Zafiro-INIA', ya que el espesor de la exina varió hasta un $60 \%$ respecto a la condición de $30 / 20{ }^{\circ} \mathrm{C}$ (Tabla III).
ETAPA DE POLEN MADURO

El grano de polen de los tres cultivares fue el típico de Poaceae, es decir esférico, monoporado, con poro provisto de annulus y opérculo (Fig. $6 \mathrm{H}, \mathrm{I}$ ). Tanto a $16{ }^{\circ} \mathrm{C}$ como a $30 / 20$ ${ }^{\circ} \mathrm{C}$ se observaron exina e intina completamente formadas (Figs. 6D-F y 3J-L). La exina se presentó estratificada en tectum, columela y capa basal, mientras que la intina se presentó a continuación de ésta como un estrato único, cuyo espesor fue equivalente entre $30-50 \%$ de la exina y con menor electrodensidad. A $16{ }^{\circ} \mathrm{C}$ se observó que el espesor de la exina disminuyó entre $20-50 \%$ en los tres cultivares estudiados (Tabla IV). A su vez, la intina redujo su espesor alrededor de $20 \%$ en 'Diamante-INIA' y 'Brillante-INIA'. En contraste, 'Zafiro-INIA' aumentó entre 50 a 80\%.

TABLA III. Espesor $(\mu \mathrm{m})$ de los estratos de la pared del grano de polen en etapa de micrósporas libres en tres cultivares de arroz a $30 / 20{ }^{\circ} \mathrm{C}$ y $16^{\circ} \mathrm{C}$ durante la etapa reproductiva.

TABLE III. Thickness $(\mu \mathrm{m})$ of pollen grain wall layers in free microspores stage in three rice cultivars to $30 / 20{ }^{\circ} \mathrm{C}$ and $16{ }^{\circ} \mathrm{C}$ during the reproductive stage.

\begin{tabular}{lccc}
\hline ETAPA DE MICRÓSPORA LiBRE & 'DiAMANTE- INIA' & 'BRILLANTE- INIA' & 'ZAFiro- INIA' \\
\cline { 2 - 4 } $30 / 20^{\circ} \mathrm{C}$ & & & \\
Exina & $0,55-0,80$ & $0,80-1,00$ & $0,85-1,00$ \\
Tectum & $0,20-0,40$ & $0,40-0,45$ & $0,45-0,55$ \\
Columela & $0,20-0,30$ & $0,20-0,30$ & $0,20-0,30$ \\
Capa basal & $0,30-0,45$ & $0,40-0,45$ & $0,3-0,35$ \\
$\underline{16^{\circ} \mathrm{C}}$ & & & \\
Exina & $1,00-1,30$ & $1,00-1,50$ & $1,50-1,80$ \\
Tectum & $0,60-0,80$ & $0,40-0,60$ & $0,60-0,65$ \\
Columela & $0,25-0,40$ & $0,40-0,50$ & $0,30-0,40$ \\
Capa basal & $0,20-0,25$ & $0,30-0,40$ & $0,50-0,60$ \\
\hline
\end{tabular}

TABLA IV. Espesor $(\mu \mathrm{m})$ de los estratos de la pared del grano de polen en etapa de polen maduro en tres cultivares de arroz a $30 / 20{ }^{\circ} \mathrm{C}$ y 16 ${ }^{\circ} \mathrm{C}$ durante la etapa reproductiva.

TABLE IV. Thickness $(\mu \mathrm{m})$ of pollen grain wall layers in mature pollen stage in three rice cultivars to $30 / 20{ }^{\circ} \mathrm{C}$ and $16{ }^{\circ} \mathrm{C}$ during the reproductive stage.

\begin{tabular}{lccc}
\hline EtAPA DE POLEN MADURO & 'Diamante- INIA' & 'Brillante- INIA' & 'ZAFiRo- INIA' \\
\cline { 2 - 4 }$\underline{30 / 20^{\circ} \mathrm{C}}$ & $0,75-0,85$ & $0,85-1,00$ & $1,00-1,50$ \\
Exina & $0,50-0,60$ & $0,30-0,50$ & $0,45-0,55$ \\
Tectum & $0,10-0,15$ & $0,25-0,30$ & $0,30-0,35$ \\
Columela & $0,15-0,20$ & $0,20-0,25$ & $0,30-0,45$ \\
Capa basal & $1,00-1,20$ & $1,15-1,30$ & $0,80-1,00$ \\
Intina & & & \\
$\underline{16{ }^{\circ} \mathrm{C}}$ & $0,60-0,80$ & $0,65-0,80$ & $0,70-0,80$ \\
Exina & $0,25-0,30$ & $0,20-0,25$ & $0,25-0,30$ \\
Tectum & $0,20-0,30$ & $0,15-0,20$ & $0,10-0,15$ \\
Columela & $0,20-0,30$ & $0,10-0,15$ & $0,15-0,20$ \\
Capa basal & $0,80-1,00$ & $0,90-1,20$ & $1,20-1,80$ \\
Intina & & & \\
\hline
\end{tabular}



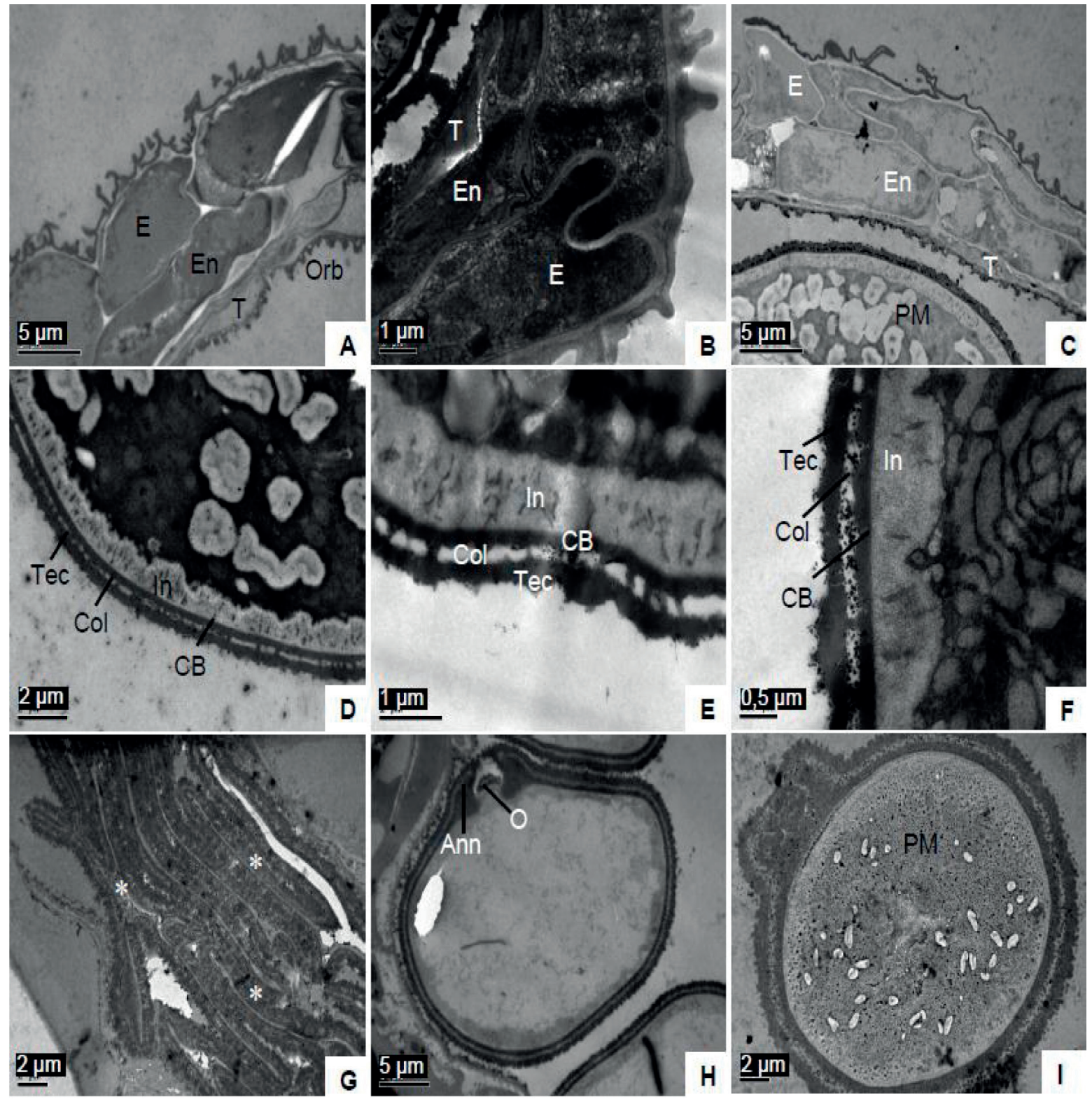

Figura 6. Fotomicrografías (MET) de la pared de la antera y exina en etapa de polen maduro, de tres cultivares de arroz a $16^{\circ} \mathrm{C}$ durante la etapa reproductiva. A, D, G. 'Diamante-INIA'. B, E, H. 'Brillante-INIA'. C, F, I. 'Zafiro-INIA'. E, epidermis; En, endotecio; T, tapete; Orb, orbículas; PM, polen maduro; Tec, Tectum; Col, columela; CB, capa basal; I, intina; Ann, annulus; O, opérculo; * , grano deforme.

Figure 6. Photomicrographs (MET) of anther wall and exine in mature pollen stage, of three rice cultivars to $16^{\circ} \mathrm{C}$ during the reproductive stage. A, D, G. 'Diamante-INIA'. B, E, H. 'Brillante-INIA'. C, F, I. 'Zafiro-INIA'. E, epidermis; En, endothecium; T, tapetum; Orb, orbicules; PM, mature pollen; Tec, Tectum; Col, columella; CB, foot layer; I, intine; Ann, annulus; O, operculum; * , deformed grain.

Respecto a la forma del grano de polen, en 'DiamanteINIA' se observó presencia de granos completamente atrofiados en el interior del lóculo, manifestándose como una contracción severa de éstos (Figs. 1G y 6G, asterisco). En 'Brillante-INIA' existió deformación a la forma de hendiduras leves en el contorno del grano (Figs. 1H y
6H). En 'Zafiro-INIA', la columela infratectal sufrió daño producto de la exposición a $16{ }^{\circ} \mathrm{C}$, cambiando la conformación de báculos simples, cortos y delgados a una forma desorganizada y con aspecto granular (Fig. 6F). Este cambio no fue observado en 'Diamante-INIA' ni en 'Brillante-INIA'. 
VIABILIDAD Y GERMINACIÓN DE POLEN EN ANTESIS

Al someter las plantas de arroz a $16{ }^{\circ} \mathrm{C}$ disminuyó la producción de granos de polen por antera entre $30-40 \%$ (Tabla V). A su vez, el porcentaje de viabilidad disminuyó entre 25 y $43 \%$, siendo visible una menor cantidad de granos teñidos de color rojo intenso con la tinción con tetrazolio, respecto a lo observado a $30 / 20{ }^{\circ} \mathrm{C}$.

En los tres cultivares a $16{ }^{\circ} \mathrm{C}$, se observó menor cantidad de granos germinados respecto de $30 / 20{ }^{\circ} \mathrm{C}$, obteniendo valores de porcentaje de germinación entre 33 y $55 \%$, mientras que a $30 / 20{ }^{\circ} \mathrm{C}$ los valores estuvieron entre 68 y 80 \% (Tabla V). El cultivar 'Diamante-INIA' fue el más afectado, ya que presentó el menor porcentaje de germinación $(33 \%)$.

Otro antecedente que cabe mencionar es que al cultivar plantas a $16{ }^{\circ} \mathrm{C}$ se retrasó el crecimiento, lo cual generó un desfase en los momentos de muestreo. Así, el primer muestreo (diez días después de estado R0) se debió realizar alrededor de 30 días después que en las plantas cultivadas en invernadero a $30 / 20{ }^{\circ} \mathrm{C}$. El segundo muestreo (veinte días después de estado R0) se realizó 30 días después que a $30 / 20{ }^{\circ} \mathrm{C}$. Finalmente, el tercer muestreo (estado de R4) se realizó 40 días después que en las plantas cultivadas a $30 / 20{ }^{\circ} \mathrm{C}$.

TABLA V. Número de granos de polen por antera, viabilidad y germinación de granos de polen en tres cultivares de arroz a $30 / 20{ }^{\circ} \mathrm{C}$ y 16 ${ }^{\circ} \mathrm{C}$ durante la etapa reproductiva.

TABLE V. Number pollen grains per anther, viability and germination of pollen grains in three rice cultivars to $30 / 20{ }^{\circ} \mathrm{C}$ and $16{ }^{\circ} \mathrm{C}$ during the reproductive stage.

\begin{tabular}{lcccccc}
\hline Cultivar & \multicolumn{2}{c}{ Granos/Antera } & \multicolumn{2}{c}{ Viabilidad (\%) } & \multicolumn{2}{c}{ Germinación (\%) } \\
\cline { 2 - 7 } & $30 / 20{ }^{\circ} \mathrm{C}$ & $16{ }^{\circ} \mathrm{C}$ & $30 / 20{ }^{\circ} \mathrm{C}$ & $16{ }^{\circ} \mathrm{C}$ & $30 / 20{ }^{\circ} \mathrm{C}$ & $16{ }^{\circ} \mathrm{C}$ \\
'Diamante-INIA' & 832 & 563 & 82 & 46 & 68 & 33 \\
'Brillante-INIA' & 897 & 596 & 86 & 54 & 75 & 41 \\
'Zafiro-INIA' & 915 & 685 & 91 & 68 & 80 & 55 \\
\hline
\end{tabular}

\section{DISCUSIÓN}

El rendimiento de grano en arroz, como también en otros cultivos de cereales, es afectado por la exposición de las plantas a estrés térmico, ya sea frío o calor, durante la etapa reproductiva. Estas condiciones provocan daño, principalmente a nivel de las estructuras reproductivas masculinas, representadas por la antera y el grano de polen (Zinn et al. 2010). La baja temperatura está asociada directamente con esterilidad de polen, afectándose con ello la polinización y, por lo tanto, la formación del fruto (Dolferus et al. 2011).

Las temperaturas mínimas extremas que causan daño por frío durante la estación cálida son el principal desastre agrometeorológico en las zonas de clima templado a nivel mundial, siendo los cultivos de arroz, sorgo, maíz y soya los más vulnerables (Fengjin \& Lianchun 2011). Entre éstos destaca el cultivo de arroz, el cual es muy sensible durante la etapa reproductiva. En otros cultivos, como garbanzo (Cicer arietinum L.), las bajas temperaturas causan abscisión floral y con ello reducen la formación de vainas; en el trigo (Triticum aestivum L.) afectan la fenología y el llenado del grano, prolongando el tiempo necesario para completar la fase de prefloración (Thakur et al. 2010).

En las observaciones realizadas en este estudio, tanto con microscopía óptica como electrónica de transmisión, se demostró que al exponer plantas de los cultivares
'Diamante-INIA', 'Brillante-INIA' y 'Zafiro-INIA' a $16^{\circ} \mathrm{C}$ durante la etapa reproductiva ocurre daño, tanto a nivel de la pared de la antera como del grano de polen. De las etapas de desarrollo evaluadas, se observó que la de micrósporas libres es la más sensible, lo que genera finalmente pérdida de viabilidad del polen. Satake \& Hayase (1970) y Gothandam et al. (2007), al evaluar arroz subsp. japonica encontraron que la etapa de tétrada es la más afectada por la disminución de temperatura $\left(12-16^{\circ} \mathrm{C}\right)$ durante el desarrollo del polen, lo que sugiere que el daño ya ocurre en una etapa anterior a la observada en este trabajo.

Por otro lado, bajo condiciones de alta temperatura, la antesis es una etapa determinante, específicamente en lo que se refiere a la dehiscencia de la antera, ya que la alta temperatura provoca incremento del déficit de presión de vapor, promoviendo la evaporación desde las anteras (Matsui \& Omasa 2002).

En los tres cultivares expuestos a $16{ }^{\circ} \mathrm{C}$ se observaron daños tanto en la pared de la antera como en los granos de polen en formación en distintas etapas del desarrollo, siendo los cultivares 'Diamante-INIA' y 'Brillante-INIA' los más afectados. La completa atrofia de los lóculos observada en algunos casos en dichos cultivares también fue mencionada por Shi et al. (2010) en anteras estériles de rábano (Raphanus sativus L.). Estos autores observaron distintos niveles de degeneración de los lóculos en la etapa de tétrada y estuvo acompañado de cierta hipertrofia de las células del tapete. 
En las observaciones de anteras de los tres cultivares expuestos a $16{ }^{\circ} \mathrm{C}$, en la etapa de micrósporas libres, se observó que el estrato más afectado corresponde al tapete, el cual presentó zonas de hipertrofia del tejido con tendencia a invadir el lóculo. Estos sectores se encuentran acompañados por la presencia de granos deformes o, en algunos casos, de ausencia de ellos. Observaciones similares fueron realizadas por Gothandam et al. (2007) al evaluar anteras de plantas de arroz subsp. japonica sometidas a disminución de temperatura $\left(16,18\right.$ y $\left.20^{\circ} \mathrm{C}\right)$ durante la etapa reproductiva. Ellos encontraron que el tapete fue el tejido más sensible al estrés por baja temperatura, provocando esterilidad masculina debido a la pérdida funcional del mismo.

Respecto de la hipertrofia en el tapete, Mamun et al. (2006) mencionan que la misma puede deberse a un incremento de la concentración de azúcar y presión de turgencia en el tejido. El incremento anormal del volumen y vacuolación de las células tapetales en plantas con esterilidad masculina sería causado por retención de moléculas que normalmente son utilizadas por las micrósporas en desarrollo o por reabsorción de azúcares derivados de la degradación prematura de la pared de calosa. A su vez, se relaciona con acumulación de almidón en los plastidios, la cual podría deberse a interrupción del transporte de carbono hacia el lóculo, incrementándose la concentración de azúcares en los estratos celulares externos de la pared de la antera (Mamun et al. 2006). En la etapa de micrósporas libres, el retículo endoplásmico (RE) de las células tapetales en plantas cultivadas a $16^{\circ} \mathrm{C}$, presentó variaciones respecto al patrón normal observado a $30 / 20^{\circ} \mathrm{C}$. Considerando que este último corresponde a pilas de sacos aplanados, las variaciones producto de la exposición a $16^{\circ} \mathrm{C}$ fueron disposición de sacos circular, serpenteada-ondulada y ondulada con tendencia a formar pilas. Esta modificación en el RE producto del estrés por baja temperatura también fue observada por Gothandam et al. (2007) quienes mencionan que los diferentes patrones de arreglo del RE pueden afectar su rol fisiológico en el desarrollo del polen, provocando esterilidad masculina. La importancia del RE radica en que es el responsable de la síntesis de proteínas, calasa, celulasa, lípidos y de la regulación del calcio (Gothandam et al. 2007). El cultivar 'Diamante-INIA' fue el más afectado por la disminución de temperatura, con cisternas del RE en las células tapetales de disposición circular. En relación a esto se considera que la forma circular o concéntrica es el resultado del estrés por disminución de temperatura, es observada en anteras estériles y se asocia a un bajo nivel de energía celular. Esto ocasiona una falla en la actividad secretora de las células tapetales, provocando con ello esterilidad masculina (Gothandam et al. 2007, Shi et al. 2010).

Otro daño observado en la etapa de micrósporas libres, producto de la exposición a $16^{\circ} \mathrm{C}$, fue la presencia de granos de polen de menor tamaño o deformes, vistos en corte con forma de medialuna. En 'Diamante-INIA' y 'Brillante-INIA' esto fue más notable y coincidió con un menor porcentaje de viabilidad y germinación de polen. Graça et al. (2005) observaron presencia de granos de polen estériles con forma de medialuna en Bromeliaceae, lo cual también estuvo relacionado con hipertrofia tapetal.

En la etapa de polen maduro en los tres cultivares evaluados, se observó que la disminución de la temperatura provocó un incremento de las estriaciones cuticulares de la epidermis de la antera. Esto fue más notorio en el cultivar 'Diamante-INIA'. Este tipo de alteración también fue observada por Mamun et al. (2006) quienes, al evaluar el efecto del frío $\left(22 / 12{ }^{\circ} \mathrm{C}\right.$, día/noche) en arroz, encontraron alteraciones tanto a nivel de la pared de la antera como del grano de polen.

Otro de los estratos de la pared de la antera que presentó alteraciones en la etapa de polen maduro a causa de la disminución de temperatura fue el tapete. En 'DiamanteINIA' se observó presencia de tapete, ya sea en contacto directo con el grano donde el espesor fue mayor respecto a los otros cultivares estudiados, o en la zona entre granos, la cual sólo estuvo presente en este cultivar. Por lo tanto, es evidente que existe un retraso en la muerte celular del estrato. El tapete se encuentra acompañado por orbículas recubriendo la cara interna, las cuales se observaron con una mayor densidad en el cultivar 'Diamante-INIA'. Li et al. (2011) mencionan que existe una relación entre el retraso en la muerte celular del tapete y la pérdida de viabilidad del polen. Ellos señalan que la ausencia de muerte celular programada del tapete y por ende la persistencia de este estrato en la etapa avanzada del desarrollo del polen, desencadena una proliferación descontrolada de las células tapetales e hinchamiento de éstas, acumulación de orbículas y desarrollo anormal de la pared del polen, provocando pérdida de viabilidad, que se manifiesta en esterilidad masculina (Li et al. 2011). En Poaceae, las orbículas han sido definidas como corpúsculos de forma variable, con un corazón central transparente a los electrones y una pared de esporopolenina con microcanales que la atraviesan y espículas superficiales (Lazarova 2003, Wang et al. 2003, Lovisolo \& Galati 2012). Representan un mecanismo de transporte de esporopolenina entre el tapete y las micrósporas en desarrollo, teniendo un rol activo en la formación de la pared del grano, específicamente la exina (Huysmans et al. 1998).

Dolferus et al. (2011) mencionan que la sensibilidad del gametofito masculino en desarrollo al estrés abiótico puede estar relacionada con las propiedades únicas del tapete. Durante la meiosis y en la etapa de micróspora joven el tapete se caracteriza por ser metabólicamente muy activo (Oliver et al. 2007). Éste cumple un rol importante en la nutrición de las micrósporas, permite la liberación de las micrósporas de la calosa mediante síntesis de calasa, secreta precursores para la síntesis de la exina y, posteriormente, se produce la muerte celular programada del tapete y restos celulares del 
mismo sirven como nutrientes para las micrósporas y se depositan como pollenkitt o trifina sobre el grano de polen maduro (Steer 1977, Pacini et al. 1985, Bedinger 1992). Tanto el estrés por frío como por sequía han demostrado ser la causa de muerte celular prematura del tapete, sugiriendo que el estrés abiótico interfiere con funciones importantes de éste. Por lo tanto, el momento en que ocurre la muerte de este tejido es crítica para la viabilidad del polen, así las variadas alteraciones metabólicas que conducen a la muerte celular prematura o retrasada del tapete causan esterilidad masculina (Oliver et al. 2007). Estos mismos autores atribuyen al ácido abscísico (ABA) un rol esencial en el control de la muerte celular programada, generando la degradación natural del tapete. Al evaluar cultivares australianos de arroz subsp. japonica, uno sensible al frío y otro tolerante, expuestos a $12{ }^{\circ} \mathrm{C}$ durante la etapa reproductiva, observaron que el ABA podría ser la señal para inducir esterilidad de polen ya que se incrementaron los niveles de ABA en la antera del cultivar sensible respecto al cultivar tolerante. En este último el nivel de ABA fue significativamente inferior tanto en condiciones normales como después del tratamiento con frío. Por otro lado, Westgate et al. (1996) observaron que el ABA en espiguillas de trigo expuesto a condiciones de estrés por sequía, también indujo esterilidad de polen.

Zinn et al. (2010) indican que, tanto el estrés por frío como por calor inducen la producción de especies de oxígeno reactivas (ROS), las cuales a elevadas concentraciones pueden causar daño oxidativo y, potencialmente, la muerte celular, especialmente en las etapas de desarrollo del polen. Por otro lado, Julia \& Dingkuhn (2013) mencionan que plantas tolerantes al frío en la etapa reproductiva tienen más enzimas antioxidantes que protegen a los tejidos.

La morfología del grano de polen de Oryza fue descrita por Chaturvedi et al. (1998). En Oryza sativa, la exina se describe como esparcidamente granulosa en vista superficial, con microscopio electrónico de barrido. Ello explica la apariencia irregular observada en el corte transversal del tectum. En el grano de polen maduro se observó que la pared carece de endexina y corresponde al tipo III de la clasificación de Walker \& Doyle (1975). Esto concuerda con observaciones de granos de polen de otras especies de cereales, tales como Triticum aestivum L., Secale cereale L., Zea mays L. y Avena sativa L. (Diethart et al. 2007).

En la etapa de polen maduro, producto de la exposición de las plantas de arroz a $16{ }^{\circ} \mathrm{C}$, el espesor de la pared del grano de polen en los tres cultivares disminuyó con respecto a las plantas cultivadas a $30 / 20{ }^{\circ} \mathrm{C}$ durante la etapa reproductiva. Según Mamun et al. (2006) los cambios en la ultraestructura celular en plantas expuestas a baja temperatura se visualizan en micrósporas con insuficiente formación de la pared del grano de polen, asociada a una pérdida funcional del tejido tapetal, causando finalmente la esterilidad del polen.

Al evaluar la viabilidad y germinación del polen se observó que los valores de estos parámetros disminuyeron al someter las plantas de los tres cultivares a $16{ }^{\circ} \mathrm{C}$. Aunque la esterilidad del polen se observó en la etapa de antesis, en la cual el polen está maduro, ello no significa que el daño por estrés abiótico haya ocurrido necesariamente en dicha etapa, sino que muchas veces es consecuencia de estrés en etapas anteriores de desarrollo. En este sentido, Dolferus et al. (2011) mencionan que, en situaciones prolongadas de estrés, que abarcan tanto la etapa de micróspora joven como la de antesis, se espera observar el efecto acumulativo del daño de ambas etapas. Por lo tanto, la esterilidad que se atribuye a estrés en antesis en realidad puede haber sido causada en la etapa de micróspora joven.

La evaluación de la viabilidad del polen en el momento de la antesis permite estimar a futuro cuánto será la pérdida de rendimiento como consecuencia de la esterilidad del polen. Además, sirve para la selección de material en los programas de mejoramiento y para determinar qué factores de manejo pueden influir en la vanazón o esterilidad floral (Ortega et al. 2011). La disminución de viabilidad del polen producto del estrés térmico, no sólo se ha observado en la subsp. japonica expuesta a condiciones de baja temperatura, sino también en la subsp. indica bajo condiciones de alta temperatura. En este sentido Chakrabarti et al. (2010) evaluaron el efecto de alta temperatura $\left(28-34{ }^{\circ} \mathrm{C}\right)$ sobre la viabilidad del polen de diferentes variedades de arroz de la subsp. indica y observaron que el aumento de temperatura incrementó la esterilidad del polen y redujo la germinación de los granos sobre el estigma. A la vez existió diferencia entre cultivares en el porcentaje de daño, tanto en la esterilidad como en la germinación del polen, demostrando que la germinación del polen en arroz no sólo es sensible al frío sino también al calor, como también se ha observado en cultivos de Arachis hypogaea y Glycine max (Wassmann et al. 2009).

La observación de un aumento en la duración de la etapa reproductiva, considerando como etapa final la antesis, causado por exposición a disminución de temperatura (16 $\left.{ }^{\circ} \mathrm{C}\right)$, concuerda con lo observado por Subedi et al. (1998) quienes, al estudiar el efecto de las bajas temperaturas $(<10$ ${ }^{\circ} \mathrm{C}$ ) desde inicio de la etapa reproductiva hasta la antesis en cultivares de trigo de invierno con diferente susceptibilidad al frío, encontraron que la baja temperatura en la etapa reproductiva incidió sobre el período de desarrollo del cultivo y la formación del grano de polen. Los cultivares sensibles al frío tardaron más tiempo en alcanzar la etapa de antesis. A nivel del grano de polen impidió la normal formación de éstos, observándose menor viabilidad de ellos. A su vez, en este último parámetro el comportamiento entre cultivares fue diferente. Estos autores destacan que un período más corto entre el inicio de la etapa reproductiva y la antesis, reduce la probabilidad de coincidir con bajas temperaturas durante el período crítico de sensibilidad a la disminución de temperatura en preantesis y con ello se limita la producción de polen estéril. Por el contrario, una 
mayor duración de este período aumenta la probabilidad de exposición de las plantas a condiciones de temperaturas desfavorables, provocando una mayor esterilidad del polen.

La mayor duración de la etapa reproductiva producto de la exposición de las plantas a bajas temperaturas, complementa lo observado por Mohammed \& Tarpley (2009), quienes evaluaron plantas de arroz subsp. japonica a alta temperatura nocturna $\left(>27^{\circ} \mathrm{C}\right)$, y observaron un acortamiento del período de crecimiento. Sin embargo, existe coincidencia en una menor viabilidad y germinación del polen y, por ende, mayor esterilidad de espiguillas. Por otro lado, en arroz la esterilidad de espiguillas inducida por alta temperatura se relaciona con disminución de la dehiscencia de la antera, menor dispersión del polen, reducida germinación de los granos de polen sobre el estigma y disminución de la elongación del tubo polínico (Prasad et al. 2006).

En arroz, tanto el estrés por alta como por baja temperatura inducen esterilidad de polen $y$ son indistinguibles a simple vista, ya que ambos producen esterilidad de espiguillas. Sin embargo, la esterilidad producida por frío es la principal y afecta mayormente durante la etapa de microsporogénesis. Es de especial interés el hecho de que la mayor sensibilidad del tapete coincide con el momento de su mayor actividad metabólica, esto es, durante la liberación de las micrósporas de la tétrada (Oliver et al. 2005). Este hecho tiene especial interés práctico pues determinar el momento de liberación de las micrósporas de la calosa permitiría evaluar el daño por frío en una etapa temprana del desarrollo. El frío que afecta el primordio de espiguilla durante esta etapa se asocia tanto con la baja temperatura del aire como con la del agua en arroz cultivado en condiciones de inundación (Ortega 2007).

El comportamiento diferente entre cultivares, al ser expuestos a $16^{\circ} \mathrm{C}$ durante la etapa reproductiva, se relaciona con lo reportado por Julia \& Dingkuhn (2013) quienes mencionan que la respuesta a la exposición a la disminución de temperatura depende del genotipo y del momento de la etapa de desarrollo del polen.

El diferente nivel de daño observado en los tres cultivares expuestos a $16^{\circ} \mathrm{C}$ posiciona a 'Diamante-INIA' como el más afectado, tanto a nivel de la pared de la antera como en la viabilidad y germinación del polen, mientras que 'ZafiroINIA' fue el menos afectado, ya que sólo se observaron algunos pocos sectores del tapete con cierta hipertrofia que tendieron a invadir el lóculo, acompañados de un reducido número de granos deformes y/o de menor tamaño. Este comportamiento diferente frente a la disminución de temperatura concuerda con los objetivos del Programa de Mejoramiento Genético de Arroz (PMGA) en el cual estos cultivares fueron creados, ya que uno de los parámetros relevantes en dicho programa es aumentar la tolerancia al frío. Teniendo en cuenta que 'Diamante-INIA' es el cultivar más antiguo (década del 70) creado en el PMGA, y 'ZafiroINIA' el más reciente (2010), se explica la mayor tolerancia al frío, expresada como un menor daño en el cultivar más reciente a nivel de la pared de la antera y del grano de polen al ser expuesto a $16^{\circ} \mathrm{C}$ durante la etapa reproductiva.

En este estudio se concluye que, durante el desarrollo del polen, la etapa de micrósporas libres es la más sensible a 16 ${ }^{\circ} \mathrm{C}$ en los tres cultivares y el tapete es el estrato de la pared de la antera más afectado por la disminución de temperatura, manifestándose como hipertrofia del tejido. A nivel del tapete, las cisternas apiladas del retículo endoplásmico están asociadas a la producción de polen fértil, mientras que el ordenamiento concéntrico de las mismas se relaciona con esterilidad del polen. A nivel del grano de polen, el daño se vincula con el espesor de la pared (exina e intina), siendo menor en granos de polen de cultivares sometidos a $16{ }^{\circ} \mathrm{C}$. Los cultivares estudiados presentaron diferente tolerancia a la disminución de temperatura, siendo 'Diamante-INIA' el menos tolerante y 'Zafiro-INIA' el más tolerante.

Numerosos autores han descrito daños a nivel celular y ultraestructural en arroz producidos por bajas temperaturas (Satake \& Hayase 1970, Nishiyama 1976, 1982, Satake \& Shibata 1992, Shimono et al. 2002, Gothandam et al. 2007, Julia \& Dingkhun 2013), no obstante, en Chile no existen antecedentes sobre el comportamiento de nuestros cultivares a estas condiciones de estrés a este nivel. Esto es necesario pues Chile es el país productor de arroz más austral del mundo y la búsqueda de nuevas variedades debe necesariamente considerar este factor. Este tipo de estudios se enmarca en programas de creación de nuevos cultivares entregando una herramienta para la evaluación temprana de la tolerancia al frío de los mismos. Futuros estudios debieran considerar la evaluación del efecto del frío en una fase más temprana, como es en etapa de tétrada y de liberación de las micrósporas que corresponde con el momento de mayor actividad del tapete y además establecer el efecto del frío en diferentes momentos de la etapa reproductiva.

\section{AGRADECIMIENTOS}

Este estudio fue financiado por CONICYT a través de la beca Magíster en Chile, año 2011. Los autores desean agradecer especialmente al personal del Laboratorio de Microscopía Electrónica de la Universidad de Concepción por su importante colaboración. A los correctores anónimos cuyas valiosas sugerencias permitieron mejorar este trabajo. A Karla Cordero, Fernando Saavedra y equipo técnico del Programa de Mejoramiento Genético de Arroz de INIAQuilamapu, por su aporte en aspectos agronómicos. A Alicia Marticorena, editora de Gayana Botánica. 


\section{REFERENCIAS}

Acevedo, M.A., W.A. Castrillo \& U.C. Belmonte. 2006. Origen, evolución y diversidad del arroz. Agronomía Tropical 56(2): 151-170.

Acevedo, R., M. Gaju, P. Tobar, M. Toro, M. Zerene, J. Lacy, R. Mutters \& G. Coвo. 2008. Rice check Chile: Manual de recomendaciones 2007/2008. Fundación Chile. Santiago, Chile. 32 pp.

Alvarado, J.R. \& P. Grau. 1991. Mejoramiento del arroz en Chile por tolerancia a frío. En: J.P. Puignau (ed.), Diálogo XXXIII. Mejoramiento de arroz. Reunión sobre mejoramiento de arroz en el Cono Sur. 17-21 julio, 1989. IICA. PROCISUR. Montevideo, Uruguay. pp. 105-114.

Alvarado, R., S. Hernaiz, A. Gómez \& F. SaAvedra. 1997. Brillante INIA, nueva variedad de arroz con grano largo y translúcido. Agricultura Técnica (Chile) 57(4): 221-222.

Bedinger, P. 1992. The remarkable biology of pollen. The Plant Cell 4: 879-887.

Bozzola, J. \& L. Russell. 1999. Electron microscopy: principles and techniques for biologists. (2nd. ed.). Jones \& Bartlett publishers. London, UK. 670 pp.

Castillo, D. \& R. Alvarado. 2002. Caracterización de germoplasma de arroz para tolerancia a frío en la etapa de germinación. Agricultura Técnica (Chile) 62(4): 596-603.

Chakrabarti, B., P.K. Aggarmal, S.D. Singh, S. Naragajan \& H. PAтHAK. 2010. Impact of high temperature on pollen germination and spikelet sterility in rice: comparison between basmati and non-basmati varieties. Crop \& Pasture Science 61: 363-368.

Chaturvedi, M., K. Datta \& P.K.K. Nair. 1998. Pollen morphology of Oryza (Poaceae). Grana 37: 79-86.

Cordero, K. 2012. Temperate rice in Chile. pp. 29-31. In: K.K. Jena \& B. Hardy (eds.). Advances in temperate rice research. International Rice Research Institute(IRRI). Los Baños, Philippines. 105 pp.

Counce, P.A., T.C. Keisling \& A.J. Mitchell. 2000. A uniform, objective, and adaptive system for expressing rice development. Crop Science 40: 436-443.

Cruz, R. Da., S. Milach \& L. Federizzi. 2006. Rice cold tolerance at the reproductive stage in a controlled environment. Scientia Agricola 63(3): 255-261.

Cruz, R. DA, S. Milach \& L. Federizzi. 2008. Inheritance of panicle exsertion in rice. Scientia Agrícola 65(5): 502-507.

Díaz, S., R. Morejón, R. CAStro \& N. Pérez. 2006. Comportamiento de genotipos de arroz (Oryza sativa L.) seleccionados para tolerancia a las bajas temperaturas en siembra temprana de frío. Cultivos Tropicales 27(2): 71-75.

Diethart, B., S. SAM \& M. WeBer. 2007. Walls of allergenic pollen: Special reference to the endexine. Grana 46: 164-175.

Dolferus, R., X. Ji \& R. Richards. 2011. Abiotic stress and control of grain number in cereals. Plant Science 181: 331-341.

Fenguin, X. \& S. Lianchun. 2011. Analysis of extreme lowtemperature events during the warm season in Northeast China. Natural Hazards 58: 1333-1344.

Gothandam, K., E. Kim \& Y. Chung. 2007. Ultrastructural study of rice tapetum under low-temperature stress. Journal of Plant Biology 50(4): 396-402.

Graça, M., C.A. Furness, C.J. Prychid \& P.J. Rudall. 2005. Microsporogenesis and anther development in
Bromeliaceae. Grana 44(2): 65-74.

Huysmans, S., G. El-Ghazaly \& E. Smets. 1998. Orbicules in Angiosperms: morphology, function, distribution, and relation with tapetum types. Botanical Review 64: 240272.

Imin, N., T. Kerim, J. Weinman \& B. Rolfe. 2006. Low temperature treatment at the young microspore stage induces protein changes in rice anthers. Molecular \& Cellular Proteomics 5(2): 274-292.

International Rice Research Institute (IRRI). 2002. Rice Almanac: source book for the most important economic activity on earth. (3rd. ed.). CABI publishing. Oxon, UK. 253 PP.

Jagadish, S.V.K, P.Q. Craufurd \& T.R. Wheeler. 2007. High temperature stress and spikelet fertility in rice (Oryza sativa L.). Journal of Experimental Botany 58(7): 16271635.

Julia, C. \& M. Dingkuhn. 2013. Predicting temperature induced sterility of rice spikelets requires simulation of cropgenerated microclimate. European Journal of Agronomy 49: $50-60$.

Kellog, E.A. 2009. The evolutionary history of Ehrartoideae, Oryzeae and Oryza. Rice 2: 1-14.

KhAtun. S. \& T.J. Flowers. 1995. The estimation of pollen viability in rice. Journal of Experimental Botany 46(282): 151-154.

LAZAROVA, N. 2003. Ultrastructure and function of barley anther tapetum. Comptes Rendus de l'Academie Bulgare des Sciences 56(3): 81-84.

Li, H., Z. Yuan, G. Vizcay-Barrena, C. Yang, W. Liang, J. Zong, Z.A. Wilson \& D. Zhang. 2011. Persistent tapetal cell1 encodes a PHD-finger protein that is required for tapetal cell death and pollen development in rice. Plant Physiology 156: $615-630$

Lovisolo, M.R. \& B.G. Galati. 2012. Diversidad de orbículas en Poaceae. Boletín de la Sociedad Argentina de Botánica 47(1-2): 87-96.

Mamun, E., S. Alfred, L. Cantrill, R. Overall \& B. Sutton. 2006. Effects of chilling on male gametophyte development in rice. Cell Biology International 30: 583-591.

Matsui, T. \& K. Omasa. 2002. Rice (Oryza sativa L.) cultivars tolerant to high temperature at flowering: anther characteristics. Annals of Botany 89: 683-687.

Mohammed, A.R. \& L. TARPLEY. 2009. High nighttime temperatures affect rice productivity through altered pollen germination and spikelet fertility. Agricultural and Forest Meteorology 149: 999-1008.

NishiYAmA, I. 1976. Male sterility caused by cooling treatment at the young microspore stage in rice plants. XIII. Ultrastructure of tapetal hypertrophy without primary wall. Proceeding of the Crop Science Society of Japan 45: 270-278.

Nishiyama, I. 1982. Male sterility caused by cooling treatment at the young microspore stage in rice plants. XXIII. Anther length, pollen number and the difference insusceptibility to coolness among spikelets on the panicle. Proceeding of the Crop Science Society of Japan 51: 462-469.

Oliver, S., J. van Dongen, S. Alfred, E. Mamun, X. Zhao, H. Saini, S. Fernandes, C. Blanchard, B. Sutton, P. Geigenberger, E. Dennis \& R. Dolferus. 2005. Cold-induced repression of the rice anther-specific cell wall invertase gene OSINV4 is correlated with sucrose accumulation and pollen sterility. 
Plant, Cell and Environment 28: 1534-1551.

Oliver, S., E. Dennis \& R. Dolferus. 2007. ABA regulates apoplastic sugar transport and is a potential signal for coldinduced pollen sterility in rice. Plant and Cell Physiology 48(9): 1319-1330.

Ortega, R. 2007. Analysis of factors affecting spikelet sterility in flooded rice under field conditions in Chile. Archives of Agronomy Soil Science 53(2): 183-192.

Ortega, R., M. Aresti \& I. Pereira. 2011. Implementation and evaluation of an image analysis system for determining viability of pollen grains in temperate rice. Chilean Journal of Agricultural Research 71(1): 16-22.

Pacini, E., G. Franchi \& M. Hesse. 1985. The tapetum: its form, function and possible phylogeny in Embryophyta. Plant Systematics and Evolution 149: 155-185.

Peterson, R., J.P. Slovin \& C. Chen. 2010. A simplified method for differential staining of aborted and non-aborted pollen grains. International Journal Plant Biology 1(13): 66-69.

Prasad, P.V.V., K.J. Boote, L.H. Allen, J.E. Sheehy \& J.M.G. Thomas. 2006. Species, ecotype and cultivar differences in spikelet fertility and harvest index of rice in response to high temperature stress. Field Crops Research 95: 398411.

Saini, H. \& M. Westgate. 2000. Reproductive development in grain crops during drought. Advances in Agronomy 68: 59-96.

Satake, T. \& H. Hayase. 1970. Male sterility caused by cooling treatment at the young microspore stage in rice plants: V. Estimations of pollen developmental stage and the most sensitive stage to coolness. Proceeding of the Crop Science Society of Japan 39: 468-473.

Satake, T. \& M. Shibata. 1992. Male sterility caused by cooling treatment at the young microspore stage in rice plants: XXXI. Four components participating in fertilization. Proceedings of the Crop Science Society of Japan 61(3): 454-462.

Shi, S., D. Ding, S. Mei \& J. WAng. 2010. A comparative light and electron microscopic analysis of microspore and tapetum development in fertile and cytoplasmic male sterile radish. Protoplasma 241: 37-49.
Shimono, H., T. Hasegawa \& K. Iwama. 2002. Response of growth and grain yield in paddy rice to cool water at different growth stages. Field Crops Research 73: 67-79.

SteEr, M. 1977. Differentiation of the tapetum in Avena: I. The cell surface. Journal of Cell Science 25: 125-138.

Stolpe, N. 2006. Descripciones de los principales suelos de la VIII Región de Chile. Publicaciones del Departamento de Suelos y Recursos Naturales, Facultad de Agronomía, Universidad de Concepción, Editorial Trama Impresores S.A., Chillán Chile. 84 pp.

Subedi, K.D., C.N. Floyd \& C.B. Budhathoki. 1998. Cool temperature-induced sterility in spring wheat (Triticum aestivum L.) at high altitudes in Nepal: variation among cultivars in response to sowing date. Fields Crop Research 55: 141-151.

Thakur, P., S. Kumar, J.A. Malik, J.D. Berger \& H. Nayyar. 2010. Cold stress effects on reproductive development in grain crops: An overview. Environmental and Experimental Botany 67: 429-443.

Walker, J.W. \& J.A. Doyle. 1975. The bases of angiosperm phylogeny: Palinology. Annals Missouri Botanical Garden 62(3): 664-723.

Wang, A., Q. Xia, W. Xie, R. Datla \& G. Selvaraj. 2003. The classical Ubisch bodies carry a sporophytically produced structural protein (RAFTIN) that is essential for pollen development. Plant Biology 100(24): 14487-14492.

Wassmann, R., S.V.K. Jagadish, S. Heuer, A. Ismail, E. Redona, R. Serraj, R.K. Singh, G. Howell, H. Pathak \& K. Sumfleth. 2009. Climate Change Affecting Rice Production: The Physiological and Agronomic Basis for Possible Adaptation Strategies. Advances in Agronomy 101: 59-122.

Westgate, M.E., J.B. Passioura \& R. Munns. 1996. Water status and ABA content of floral organs in drought-stressed wheat. Australian Journal of Plant Physiology 23: 763-772.

Zinn, K.E., M. Tunc-Ozdemir \& J.F. Harper. 2010. Temperature stress and plant sexual reproduction: uncovering the weakest links. Journal of Experimental Botany 61(7): 1959-1968.

Recibido: 12.12 .13

Aceptado: 16.06.14 